\title{
Hubungan Tingkat Pengetahun dan Dukungan Suami Terhadap Pemberian Imunisasi Dasar Lengkap Pada Bayi
}

\author{
Afzahul Rahmi \\ Program Studi Kesehatan Masyarakat, STIKes Alifah Padang \\ Jl. Khatib Sulaiman No.52B, Kel. Ulak Karang Sel., Padang Utara, Kota Padang, Sumatera Barat 25134 \\ Email : afzahul_rahmi@yahoo.co.id
}

\begin{abstract}
Abstrak
Data menunjukkan lebih dari 1,4 juta anak di dunia meninggal karena penyakit yang dapat dicegah dengan imunisasi (PD3I). Di Indonesia tahun 2014 ditemukan 84 kasus tetanus neonatorum, kasus campak 12.943, kasus difteri 396 kasus. Tujuan penelitian adalah mengetahui hubungan pengetahuan dan dukungan suami terhadap pemberian imunisasi dasar lengkap pada bayi di RW 10 Parupuak Tabing Kota Padang. Jenis Penelitian kuantitatif dengan pendekatan cross sectional study. Penelitian dimulai pada tangal 02 - 07 Agustus 2018. Populasi Penelitian ini adalah ibu yang mempunyai balita yang berada di $R W 10$ Parupuak Tabing Kota Padang. Teknik pengambilan sampel dengan Simple Random Sampling. Pengumpulan data melalui angket menggunakan kuesioner, analisis penelitian menggunakan analisis univariat dan analisis bivariat menggunakan uji Chi-Square. Penelitian ini menunjukkan 69.8\% tidak di imunisasi dasar lengkap. 58,5\% memiliki tingkat pengetahuan rendah, dan 69,8\% tidak mendapatkan dukungan suami dalam pemberian imunisasi dasar lengkap. Hasil uji statistik menunjukkan terdapat hubungan tingkat pengetahuan, sikap dan dukungan suami terhadap pemberian imunisasi dasar lengkap pada bayi (p-value <0,05).
\end{abstract}

Kata kunci: Tingkat Pengetahuan, Dukungan Suami, Imunisasi Dasar

\section{Association Between Knowledge Level and Husband's Support of Baby With Completed Basic Immunizations}

\begin{abstract}
Every year more than 1.4 million children in the world die from various diseases that can be prevented by immunization. Indonesia's health profile in 2014 showed 84 cases of tetanus neonatorum, 12.934 cases of measles, and 396 cases of diphtheria, for that it's mandatory to provide complete basic immunization to prevent PD3I. This study aims to determine the factors associated with complete basic immunization in infants in RW 10 Parupuk Tabing Village of the Lubuk Buaya Public Health Center in Padang in 2018.This type of research is quantitative with a cross-sectional study approach. The population of this study was mothers who had toddlers who were in RW 10, ParupukTabing Village, the Performance Area of the Lubuk Buaya Health Center in Padang City. The sampling technique is a simple random sampling method. Data collection through questionnaires using questionnaires. Analysis of the study using univariate analysis and bivariate analysis using Chi-square test.The results showed that $69.8 \%$ did not provide complete basic immunization in infants, 58.5\% had a low level of knowledge, and $69.8 \%$ did not get husband's support in providing complete basic immunization in infants. Statistical test results show there is a relationship between the level of knowledge, attitude and support of the husband with complete basic immunization in infants with (p-value <0.05).
\end{abstract}

Keyword: Level of knowledge, Husband's support, Basic Immunization 


\section{PENDAHULUAN}

Berdasarkan Undang-Undang Nomor 36 Tahun 2009 tentang Kesehatan, Imunisasi adalah usaha untuk mencegah timbulnya penyakit menular yang merupakan kegiatan prioritas Kementerian Kesehatan sebagai bentuk nyata komitmen pemerintah untuk mencapai Sustainable Development Goals (SDGs) terutama untuk menurunkan angka kematian pada anak (Permenkes RI, 2017).

Lebih dari 1,4 juta anak di dunia meninggal disebabkan berbagai penyakit yang dapat dicegah dengan imunisasi. Rencana Pembangunan Jangka Menengah (RPJMN) Kesehatan periode 2015-2019 yaitu tercapainya cakupan IDL 93\% pada usia 0-11 bulan pada tahun 2015 diharapkan pencapaian sebesar 91\%, pada tahun $2016(91,5 \%)$, tahun 2017 (92\%), tahun 2018 (92,5\%), dan tahun 2019 bisa mencapai 93\%. Dengan demikian, untuk mencapai hasil tersebut,dilakukan melalui program imunisasi (Kemenkes RI, 2015).

Berdasarkan hasil World Health Organization (WHO) (2016), terdapat 21,8 juta anak tahun 2013 tidak diberikan imunisasi. Pemberian imunisasi dapat mencegah 2-3 juta orang meninggal setiap tahun akibat penyakit campak 540.000 (38\%), Pneumonia 386.000 (27\%), pertusis 294.000 (20\%) dan tetanus 198.000 (14\%), sedangkan tahun 2014 terdapat 18,7 juta bayi didunia tidak diberi imunisasi rutin DPT3 yang lebih dari $60 \%$ dari anak-anak tinggal di 10 negara termasuk Indonesia (Kementrian Kesehatan RI, 2016).

\section{METODE PENELITIAN}

\footnotetext{
Penelitian ini merupakan analitik dengan menggunakan pendekatan crosssectional study yaitu mengetahui hubungan antara variabel independen (sikap dan dukungan suami) dengan variabel dependen (Pemberian imunisasi dasar) di amati dan di ukur dalam waktu yang bersamaan. Penelitian ini dilakukan di RW 10 Kelurahan Parupuak Tabiang Kota
}

Menurut Profil kesehatan Indonesia pada tahun 2014 menunjukkan 84 kasus tetanus neonatorum, 12.943 kasus campak, dan 396 kasus difteri, oleh sebab itu diwajibkan dapat memberikan imunisasi dasar lengkap untuk mencegah PD3I tersebut. Cakupan imunisasi lengkap di Indonesia tahun 2014 sebesar 86,9\% yaitu tidak mencapai target Renstra sebesar 90\%. Di Indonesia Angka kematian Bayi (AKB) masih tinggi bila di bandingkan dengan negaranegara di ASEAN. Secara Nasional Angka kematian Bayi (AKB) sebesar 246/100.000 kelahiran hidup.

Berdasarkan data Dinas Kesehatan Provinsi Sumatera Barat, beberapa indikator pemberian imunisasi masih ada beberapa yang belum tercapai. Untuk capaian imunisasi kontak pertama, imunisasi BCG, polio 1 dan DPT-HB1 sudah mencapai target $80 \%$ dan hanya imunisasi BCG $(76,85 \%)$ yang belum mencapai target, untuk capaian imunisasi lengkap, polio 4, DPT-HB3 telah mencapai target sebanyak $85 \%$, hanya campak yang belum tercapai targetnya karena ada anggapan negatif tentang imunisasi yang haram dan tidak efektif (Dinas Kesehatan Provinsi Sumatera Barat, 2012).

Tujuan penelitian adalah mengetahui hubungan pengetahuan dan dukungan suami terhadap pemberian imunisasi dasar lengkap pada bayi di RW 10 Parupuak Tabing Kota Padang.

Padang. Waktu penelitian dilakukan pada bulan Februari-Juli 2018. Sampel berjumlah 53 orang dengan teknik pengambilan sampel adalah simple random sampling. Teknik analisis data menggunakan analisis univariat dan bivariat dimana analisis bivaria menggunakan chi-square. 


\section{HASIL DAN PEMBAHASAN}

\section{A. Univariat}

\section{Pemberian Imunisasi Dasar Lengkap}

Tabel 1. Distribusi Proporsi Responden Berdasarkan Pemberian Imunisasi Dasar Lengkap pada Bayi

\begin{tabular}{lcc}
\hline \multicolumn{1}{c}{ Pemberian Imunisasi Dasar Lengkap } & $\boldsymbol{f}$ & $\boldsymbol{\%}$ \\
\hline Tidak Lengkap & 37 & 69.8 \\
Lengkap & 16 & 30.2 \\
\hline Total & 53 & 100 \\
\hline
\end{tabular}

Berdasarkan tabel 1 menemukan proporsi sebesar $69,8 \%$ responden tidak melakukan pemberian imunisasi secara secara lengkap kepada anaknya.Tingginya proporsi ini disebabkan oleh pengetahuan responden tentang pemberian imunisasi dasar lengkap pada bayi sebanyak 58,5\% sehingga responden kurang memahami pentingnya dalam pemberian imunisasi dasar lengkap.

Imunisasi berasal dari kata imun, kebal atau resisten. Anak diimunisasi, artinya diberikan kekebalan terhadap suatu penyakit tertentu. Anak bisa kebal terhadap suatu penyakit tetapi belum tentu kebal dengan penyakit yang lain. Imunisasi adalah upaya untuk meningkatkan kekebalan seseorang secara aktif terhadap suatu penyakit, sehingga bila suatu saat terpapar terhadap penyakit tersebut tidak akan sakit atau hanya mengalami sakit ringan (Pudiklat Nakes Kemenkes RI, 2014)

Pendidikan mempengaruhi pengetahuan responden, menurut (Soekidjo Notoadmojdo, 2012). pendidikan adalah suatu upaya persuasi kepada masyarakat, supaya masyarakat mau melakukan tindakan-tindakan (praktik) untuk memelihara dan meningkatkan kesehatannya.Tindakan pemeliharaan dan peningkatan kesehatan yang dihasilkan dari pendidikan kesehatan didasarkan atas pengetahuan dan kesadarannya melalui proses pembelajaran, sehingga perilaku tersebut diharapkan akan berlangsung lama (long lasting) dan menetap (langgeng).

\section{Tingkat Pengetahuan}

Tabel 2. Distribusi Proporsi Responden Berdasarkan Tingkat Pengetahuan Terhadap Pemberian Imunisasi Dasar Lengkap pada Bayi

\begin{tabular}{lcc}
\hline \multicolumn{1}{c}{ Tingkat Pengetahuan } & $\boldsymbol{f}$ & $\boldsymbol{\%}$ \\
\hline Rendah & 31 & 58.5 \\
Tinggi & 22 & 41.5 \\
\hline Total & 53 & 100 \\
\hline
\end{tabular}

Berdasarkan tabel 2 diperoleh jumlah responden yang memiliki pengetahuan rendah sebanyak 31 ibu $(58,5 \%)$ dan pengetahuan tinggi sebanyak $22 \mathrm{ibu}$
(41,5\%). Rendahnya tingkat pengetahuan responden selain disebabkan karena pendidikan juga disebabkan kurangnya informasi mengenai pentingnya kesehatan 
anak dan pemberian imunisasi dasar lengkap.

Hasil penelitian ini hampir sama dengan penelitian (Emilya, 2014), yang berjudul "Hubungan Pengetahuan dan Sikap Ibu Balita dengan Tindakan Imunisasi Dasar Lengkap di Kelurahan Lambung Bukit Kota Padang” yaitu dari 40 responden sebanyak 24 ibu $(62,5 \%)$ memiliki tingkat pengetahuan rendah terhadap imunisasi dasar.

Pengetahuan merupakan hasil tahu seseorang terhadap objek melalui indra yang dimilikinya (mata, hidung, telinga, dan sebagainya). Sebagian pengetahuan seseorang diperoleh berdasarkan indra pendengaran (telinga) dan penglihatan (mata). Pengetahuan seseorang terhadap objek memiliki intensitas atau tingkat yang berbeda-beda (Soekidjo Notoadmodjo, 2014)

Hasil penelitian yang sudah dilakukan sebagian besar pengetahuan responden tentang pemberian imunisasi dasar lengkap masih rendah karena responden hanya sebatas tau apa yang dimaksud dengan pemberian imunisasi tetapi tidak mengaplikasikan langsung kepada anak sehingga responden minim akan informasi mengenai pentingnya kesehatan anak dan pemberian imunisasi dasar lengkap.

Rendahnya tingkat pengetahuan yang dimiliki responden juga disebabkan karena tingkat pendidikan yang masih relatif rendah. Pengetahuan erat hubungannya dengan pendidikan, karena dengan pendidikan yang tinggi maka akan tinggi pula pengetahuannya. Namun perlu ditekankan bukan berarti seseorang yang mempunyai pendidikan rendah mutlak berpengetahuan rendah karena pengetahuan tidak hanya dimiliki dari pendidikan formal saja, tetapi juga bisa diperoleh dari pendidikan non formal (A, Wawan, 2010).

\section{Dukungan Suami}

Tabel 3. Distribusi Proporsi Responden Berdasarkan Dukungan Suami Terhadap Pemberian Imunisasi Dasar Lengkap Pada Bayi

\begin{tabular}{lcc}
\hline \multicolumn{1}{c}{ Dukungan Suami } & $\boldsymbol{f}$ & $\boldsymbol{\%}$ \\
\hline Tidak Mendukung & 37 & 69.8 \\
Mendukung & 16 & 30.2 \\
\hline Total & 53 & 100 \\
\hline
\end{tabular}

Berdasarkan tabel 3 didapatkan hasil penelitian terhadap 53 responden terdapat 37 responden $(69,8 \%)$ tidak didukung dengan baik oleh suami saat pemberian imunisasi dasar lengkap.

Dalam buku (Friedman, 2010) Menurut U.S Bureau of the Census menggunakan defenisi keluarga yang berorientasi tradisional yaitu keluarga terdiri atas individu yang bergabung bersama oleh ikatan pernikahan, darah atau adopsi dan tinggal dalam satu rumah yang sama. Keluarga inti (terkait dengan pernikahan), keluarga yang terbentuk karena pernikahan, peran sebagai orang tua atau kelahiran, terbagi dari suami, istri dan anak-anak mereka (biologis, adopsi) atau keduanya. Keluarga orientasi (keluarga asal), unit keluarga tempat seseorang dilahirkan. Keluarga family, keluarga inti dan individu terkait lainnya (oleh hubungan darah), yang biasanya merupakan anggota keluarga asal dari salah satu pasangan keluarga inti, keluarga ini terbagi atas sanak saudara, mencangkup nenek/kakek, bibi, paman, keponakan dan sepupu.

Keluarga sebagai unit pelayanan perawatan, keluarga adalah unit utama dari masyarakat dan merupakan lembaga yang menyangkut kehidupan bermasyarakat. Keluarga sebagai kelompok dapat menimbulkan, mencegah, mengabaikan, masalah 
kesehatan dalam kelompoknya (Harmoko, 2012).

Hal yang mempengaruhi dukungan suami terhadap pelaksanaan imunisasi dasar lengkap salah satunya keadaan sosial ekonomi masyarakat yang masih tergolongan menengah ke bawah sehingga suami sebagai kepala keluarga lebih memprioritaskan diri untuk mencari nafkah dibandingkan memperhatikan kebutuhan kesehatan anaknya. Maka perlu dilakukan upaya promosi kesehatan khususnya tentang pemberian imunisasi, agar suami mengetahuai bahwa dukungan dari seorang suami memegang peranan penting untuk membentuk suatu perilaku dalam diri ibu karena dengan adanya dukungan akan menjadikan keadaan dalam diri ibu muncul, terarah dan mempertahankan perilaku untuk memberikan imunisasi campak sesuai dengan umur yang telah ditentukan. Sesuai teori menurut (Friedman, 2010) dukungan suami masuk di dalam dukungan sosial keluarga, dimana mengacukepada dukungan-dukungan sosial yang dipandang oleh anggota keluarga sesuatu yang dapat diakses untuk keluarga. Dukungan sosial keluarga dimaksudkan berupa dukungan dari suami/isteri, dukungan saudara kandung, orang tua, kerabat, juga tetangga.

\section{B. Bivariat}

Tabel 4. Hubungan Tingkat Pengetahuan dengan Pemberian Imunisasi Dasar Lengkap pada Bayi

\begin{tabular}{|c|c|c|c|c|c|c|c|}
\hline \multirow{3}{*}{$\begin{array}{c}\text { Tingkat } \\
\text { Pengetahuan }\end{array}$} & \multicolumn{4}{|c|}{$\begin{array}{c}\text { Pemberian Imunisasi Dasar } \\
\text { LengkapPada Bayi }\end{array}$} & \multirow{2}{*}{\multicolumn{2}{|c|}{ Total }} & \multirow{3}{*}{$\begin{array}{c}p \\
\text { value }\end{array}$} \\
\hline & \multicolumn{2}{|c|}{ Tidak Lengkap } & \multicolumn{2}{|c|}{ Lengkap } & & & \\
\hline & $f$ & $\%$ & $f$ & $\%$ & $f$ & $\%$ & \\
\hline Rendah & 28 & 90,3 & 3 & 9,7 & 31 & 100 & \\
\hline Tinggi & 9 & 40,9 & 13 & 59,1 & 22 & 100 & 0,000 \\
\hline Jumlah & 37 & 69,8 & 16 & 30,2 & 53 & 100 & \\
\hline
\end{tabular}

Berdasarkan tabel 4 terhadap 53 responden didapatkan proporsi pemberian imunisasi pada bayi yang tidak lengkap lebih banyak pada responden berpengetahuan rendah $(90,3 \%)$ dibandingkan responden berpengetahuan tinggi $(40,9 \%)$ yang berarti adanya hubungan yang signifikan antara tingkat pengetahuan terhadap pemberian imunisasi dasar lengkap pada bayi.

Pengetahuan atau kognitif merupakan domain yang begitu penting agar terbentuknya tindakan seseorang (ovent behavior). Perilaku yang berdasarkan oleh pengetahuan akan lebih langgeng dari pada prilaku yang tidak berdasarkan pengetahuan.
Berdasarkan penelitian tingginya tingkat pengetahuan responden tentang imunisasi dasar dipengaruhi oleh kualitas pelayanan yang baik dari petugas kesehatan dalam hal memberikan informasi atau penyuluhan kesehatan kepada masyarakat. Semakin tinggi pengetahuan seseorang tentang imunisasi, memungkinkan orang tersebut untuk mengaplikasikan pengetahuannya dalam hal memberikan imunisasibayinya secara lengkap. 
Tabel 5. Hubungan Dukungan Suami dengan Pemberian Imunisasi Dasar Lengkap pada Bayi

\begin{tabular}{|c|c|c|c|c|c|c|c|}
\hline \multirow{3}{*}{$\begin{array}{l}\text { Dukungan } \\
\text { Suami }\end{array}$} & \multicolumn{4}{|c|}{$\begin{array}{c}\text { Pemberian Imunisasi Dasar } \\
\text { LengkapPada Bayi }\end{array}$} & \multirow{2}{*}{\multicolumn{2}{|c|}{ Total }} & \multirow{3}{*}{$\begin{array}{c}p \\
\text { value }\end{array}$} \\
\hline & \multicolumn{2}{|c|}{ Tidak Lengkap } & \multicolumn{2}{|c|}{ Lengkap } & & & \\
\hline & $f$ & $\%$ & $f$ & $\%$ & $f$ & $\%$ & \\
\hline Tidak Mendukung & 31 & 83,8 & 6 & 16,2 & 37 & 100 & \\
\hline Mendukung & 6 & 37,5 & 10 & 62,5 & 16 & 100 & 0,002 \\
\hline Jumlah & 37 & 69,8 & 16 & 30,2 & 53 & 100 & \\
\hline
\end{tabular}

Berdasarkan tabel 5 didapatkan hasil penelitian terhadap 53 responden didapatkan proporsi pemberian imunisasi pada bayi yang tidak lengkap lebih banyak pada responden yang suami tidak mendukung $(83,8 \%)$ dibandingkan responden yang suami mendukung $(37,5 \%)$ yang berarti terdapat hubungan yang signifikan antara dukungan suami responden terhadap pemberian imunisasi dasar lengkap pada bayi.

Menurut penelitian Kusrini (2014) di wilayah kerja Puskesmas Tatakarya Lampung Utara terhadap 67 responden menunjukkan bahwa sebanyak $(46,27 \%)$ memiliki suami tidak mendukung dan $(53,73 \%)$ memiliki suami mendukung dalam pemberian imunisasi dan ditemukan ada

\section{SIMPULAN}

Lebih dari separuh $(69,8 \%)$ ibu tidak melakukan imunisasi dasar lengkap pada bayi di RW 10 Kelurahan Parupuk Tabing Kota Padang. Lebih dari separuh $(58,5 \%)$ ibu memiliki pengetahuan rendah terhadap imunisasi dasar lengkap pada bayi di RW 10 Kelurahan Parupuk Tabing Kota Padang.Lebih dari separuh $(69,8 \%)$ ibu tidak mendapatkan dukungan suami dalam pemberian imunisasi dasar lengkap pada bayi di RW 10 Kelurahan Parupuk Tabing Kota Padang. hubungan dukungan suami dengan pemberian imunisasi.

Oleh karena itu sangat dibutuhkan sosialisasi terkait pemberian imunisasi kepada ibu balita dan suami dengan memberikan pengetahuan mengenai pentingnya imunisasi, maka suami bisa memberi dukungan kepada istri untuk memberikan imunisasi. Dukungan suami memiliki hubungan terhadap pemberian imunisasi pada anak, diharapkan tenaga kesehatan dapat memberikan penyuluhan dan komunikasi ,informasi dan edukasi tentang keterlibatan suami yang salah satu faktor pendorong bagi responden untuk memberikan masukan.

Ada hubungan tingkat pengetahuan terhadap pemberian imunisasi dasar lengkap pada bayi di RW 10 Kelurahan Parupuk Tabing Kota Padang. Ada hubungan dukungan suami terhadap pemberian imunisasi dasar lengkap pada bayi di RW 10 Kelurahan Parupuk Tabing Kota Padang.

\section{UCAPAN TERIMAKASIH}

Pada kesempatan ini peneliti mengucapkan terimakasih kepada Ketua STIKes Alifah Padang, Kepala Dinas Kota Padang yang telah membantu pelaksanaan penelitian ini. 


\section{DAFTAR PUSTAKA}

A, Wawan, D. M. (2010). Teori dan pengukuran Pengetahuan, Sikap dan. Perilaku Manusia. Yogyakarta: Nuha Medika.

Dinas Kesehatan Provinsi Sumatera Barat. (2012). Profil Kesehatan Provinsi Sumatera Barat. Sumatera Barat.

Emilya, S. (2014). Hubungan Pengetahuan dan Sikap Ibu Balita terhadap Tindakan Imunisasi Dasar Lengkap di Kelurahan Lambung Bukit Kota Padang Tahun 2014. Jurnal Kesehatan Andalas.

Friedman, M. (2010). Buku Ajar Keperawatan keluarga: Riset, Teori, dan Praktek. Edisi ke-5. Jakarta: EGC.
Harmoko. (2012). Asuhan Keperawatan Keluarga. Yogyakarta: Pustaka Pelajar.

Kemenkes RI. (2015). Profil Kesehatan Indonesia. Jakarta: Kemenkes.

Kementrian Kesehatan RI. (2016). Profil Kesehatan Indonesia. Jakarta: Kemenkes.

Permenkes RI. (2017). Penyelenggara Imunisasi. Jakarta.

Pudiklat Nakes Kemenkes RI. (2014). Buku Ajar Imunisasi. Jakarta: Kemenkes RI.

Soekidjo Notoadmodjo. (2014). Ilmu Prilaku Kesehatan. Jakarta: Rineka Cipta.

Soekidjo Notoadmojdo. (2012). Promosi Kesehatan dan perilaku Kesehatan. Jakarta: Rineka Cipta. 